\title{
Modeling of Thin-layer Sun Drying of Slices of Meat in Kilishi Form
}

\author{
Aboubacar Chaibou Aouta ${ }^{1,}$, , Haoua Amadou ${ }^{1}$, Eloi Salmwendé Tiendrebeogo ${ }^{2}$ \\ ${ }^{1}$ Laboratoire d'Informatique Fondamentale et Appliquée-Sciences de l'Ingénieur, Université Abdou Moumouni, Niamey, Niger \\ ${ }^{2}$ Laboratoire de Physique et de Chimie de l'Environnement (LPCE), Université Joseph Ki-Zerbo, Ouagadougou, Burkina Faso
}

Email address:

chaibouboukar@gmail.com (A. C. Aouta)

${ }^{*}$ Corresponding author

\section{To cite this article:}

Aboubacar Chaibou Aouta, Haoua Amadou, Eloi Salmwendé Tiendrebeogo. Modeling of Thin-layer Sun Drying of Slices of Meat in Kilishi Form. Science Journal of Energy Engineering. Vol. 8, No. 2, 2020, pp. 25-32. doi: 10.11648/j.sjee.20200802.12

Received: August 6, 2020; Accepted: August 24, 2020; Published: September 7, 2020

\begin{abstract}
The sun-drying method is one of the methods used to dry kilishi in Niger and throughout Sub-Saharan Africa. It is a purely traditional process, which only requires the knowledge of the butcher. The objective of our work consists of, on the one hand, the evaluation study of the drying in the sun in a thin layer of slices of meat in the form of kilishi, in typically Sahelian climatic conditions and, on the other hand, the study of mathematical modeling of the physical process which takes place during this drying. The methodological approach consists in establishing a mathematical model, which predicts the thermal and mass balance of the product during the drying process and validates this model with an experimental test. The equations of the mathematical model governing the drying system are solved by the numerical method of Runge - Kutta in the 4th order. The results of the sun-drying evaluation study made it possible to determine the temperature evolution of the upper and lower side of the meat slices in kilish form, during the entire drying process. The monitoring of the loss of masses of the slices of meat allowed us to determine experimentally the water content as a function of time and the drying rate as a function of the water content. The comparison of the results of the numerical simulation of the mathematical model and those recorded experimentally are consistent. The relative errors between the simulation results and the experimental results are given by the statistical parameters $\mathrm{R}^{2}$, MSE and RMSE. We have obtained for the set of values of $\mathrm{R}^{2}$ close to one (1) and MSE, RMSE close to zero (0). This allowed us to conclude that the model is satisfactory.
\end{abstract}

Keywords: Thin-layer Drying, Mathematical Model, Thermal and Mass Balance

\section{Introduction}

Meat is a food that degrades at a speed that depends on various factors: it's acidity, ambient humidity, presence of pathogens, temperature [1], it is therefore essential to use a conservation treatment. It's in that regard that for decades traditional techniques have been used for processing and preserving meat. These traditional techniques often combine solar drying with other processes such as salting, frying, smoking and fermentation, thus giving rise to various traditional meat products such as biltong in South Africa, charqui in Brazil and kilishi in Sub-Saharan Africa [2]. The term kilishi comes from the Hausa jargon which means 'thin slice of dried and spicy meat' '. It's a food obtained from the transformation of boned beef or/and sheep meat. Its production and consumption has spread throughout Sub-Saharan Africa. Kilishi can be preserved for more than six months in a dry place, on the condition of being well-dried [3]. Currently in the subregion, particularly in Niger, kilishi is dried generally in traditional way; the slices of meat are dried in outdoors directly under the sun. The objective of this work is to evaluate the actual traditional solar drying process of kilishi through a mathematical model which predicts the thermal and mass balance of the product during the drying process. This model will then be validated by an experimental study. 


\section{Materials and Methods}

\subsection{Experimental Protocol}

\subsubsection{Product Preparation}

The fresh meat used in this study is purchased by a butcher specialized in the production of kilishi. It only consists of muscle from a healthy animal slaughtered and certified by the animal service. Before cutting the meat into slices, the trimming is applied to it, which consists in ridding the meat of all impurities (tendons, aponeuroses and fat) surrounding it. The meat obtained thereafter is cut into large pieces and then into thin slice strips of few millimeters thick. The thin strips of meat slice obtained are measured and weighed before being spread on a mat for the drying process.

\subsubsection{Equipment Used}

The main components of the drying process device are:

a table and a drying mat made out of millet stalks, on which is spread the product during the drying process;

an electronic scale (PRECISA-205 A), which is used for weighing the product;

Multichannel portable temperature meter (JINKO-JK804) with thermocouples to monitor the temperature evolution of the product sides during the drying process.

a laboratory oven (PROLABO FD 115), which is used to determine the dry mass of the product.

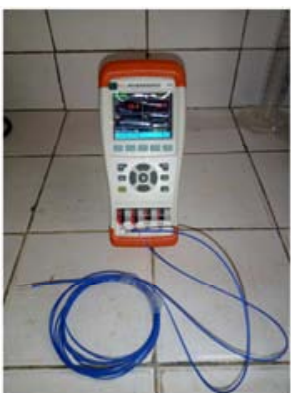

(a)

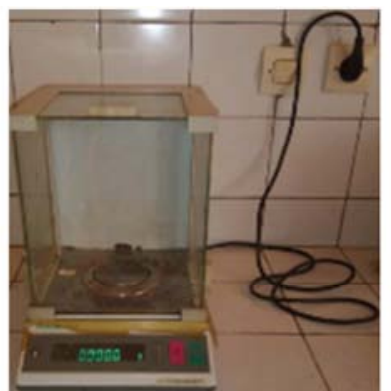

(b)

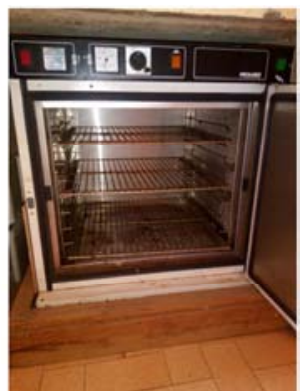

(c)

Figure 1. The main equipment used (a: Data logger with Thermocouple, b: Electronic scale, c: Laboratory oven).

Table 1. Specifications of Multichannel portable temperature meter (JINKO-JK804) with thermocouples.

\begin{tabular}{ll}
\hline B Display: & 5 digits \\
Min and Max Reading: & $-200.0^{\circ} \mathrm{C}$ to $1800.0^{\circ} \mathrm{C}$ \\
Interface: & $\mathrm{USB}, \mathrm{MICRO} \mathrm{SD}, \mathrm{PC}$ \\
Thermocouple Type: & $\mathrm{T}, \mathrm{K}, \mathrm{J}, \mathrm{N}, \mathrm{E}, \mathrm{S}, \mathrm{R}$ \\
Thermocouple Accuracy used & $\pm 0.5^{\circ} \mathrm{C}$ \\
\hline
\end{tabular}

Table 2. Specifications of Electronic scale (PRECISA-205 A).

\begin{tabular}{ll}
\hline Capacity & 0.0001 \\
Range $\left(\mathrm{g} / \mathrm{cm}^{3}\right)$ & $205 \mathrm{~g}$ \\
Scale Accuracy & \pm 0.1 \\
\hline
\end{tabular}

Table 3. Specifications of Laboratory oven (PROLABO FD 115).

\begin{tabular}{ll}
\hline Internal dimensions: & $500 \times 510 \times 415 \mathrm{~mm}$ \\
Temperature range: & Ambient to $+70^{\circ} \mathrm{C}$ \\
\hline
\end{tabular}

\subsubsection{Procedure}

The measurements took place on March 29, 2020 at the Faculty of Science and Technology of Abdou Moumouni University. The obtained thin strips of meat slice, with a thickness of about $3 \mathrm{~mm}$, are spread on a drying mat and exposed outdoors under the sun. The drying mat is placed on a table to protect the product from sand through the wind. Temperature sensors coupled with a data acquisition system are attached to both sides of the product in order to monitor the temperature evolution of the top and bottom sides of the product during the drying process. The different mass measurements are done at a sequential time interval of $5 \mathrm{~min}$ at the start of the drying process, then $10 \mathrm{~min}$, then $20 \mathrm{~min}$ and finally $30 \mathrm{~min}$ during the remaining drying process. To determine the mass of dry matter of the product at the end of the drying process, the samples are weighed and put in an oven at $105^{\circ} \mathrm{C}$ for 24 hours. The water content values on a dry basis obtained experimentally are calculated by the following relation [4]:

$$
X_{t}=\frac{m_{t}-m_{s}}{m_{s}}
$$

With $m_{t}, m_{s}$ and $X_{t}$ respectively the mass in function time, the mass of the dry product and the water content in function of time

During this process, we studied six samples of meat slices, two of which were for monitoring the change in temperature of the top and bottom sides of the product, and four samples for monitoring the change in mass loss of the product during the drying. The remainder of meat slices with irregular shapes were not studied in this work. The values of the initial masses of the studied samples as well as their dimensions are shown in the following tables:

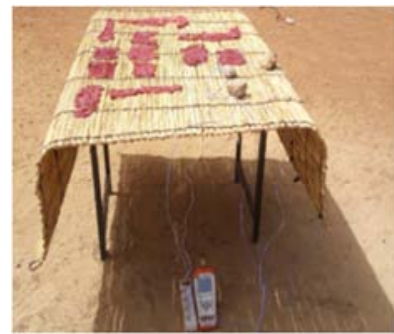

(a)

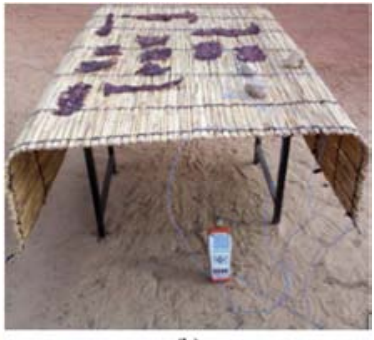

(b)
Figure 2. Drying the slices of meat outdoors under the sun ((a): Beginning of the drying process, (b): End of the drying process). 
Table 4. Samples studied for monitoring the product's temperature.

\begin{tabular}{lllll}
\hline Sample & $\begin{array}{l}\text { Initial mass } \\
\text { in g }\end{array}$ & Length (cm) & Width (cm) & $\begin{array}{l}\text { Thickness } \\
\text { (mm) }\end{array}$ \\
\hline A1 & 63.24 & $\sim 16$ & $\sim 12$ & $\sim 3$ \\
A2 & 52.31 & $\sim 15$ & $\sim 11$ & $\sim 3$ \\
\hline
\end{tabular}

Table 5. Samples studied for monitoring the product's mass loss.

\begin{tabular}{lllll}
\hline Sample & $\begin{array}{l}\text { Initial mass } \\
\text { in g }\end{array}$ & Length $(\mathbf{c m})$ & Width $(\mathbf{c m})$ & $\begin{array}{l}\text { Thickness } \\
\text { (mm) }\end{array}$ \\
\hline B1 & 36.24 & $\sim 13$ & $\sim 10$ & $\sim 3$ \\
B2 & 35.49 & $\sim 13$ & $\sim 10$ & $\sim 3$ \\
B3 & 53.16 & $\sim 15$ & $\sim 11$ & $\sim 3$ \\
B4 & 53.18 & $\sim 15$ & $\sim 11$ & $\sim 3$ \\
\hline
\end{tabular}

$\sim$ : Significantly equal to.
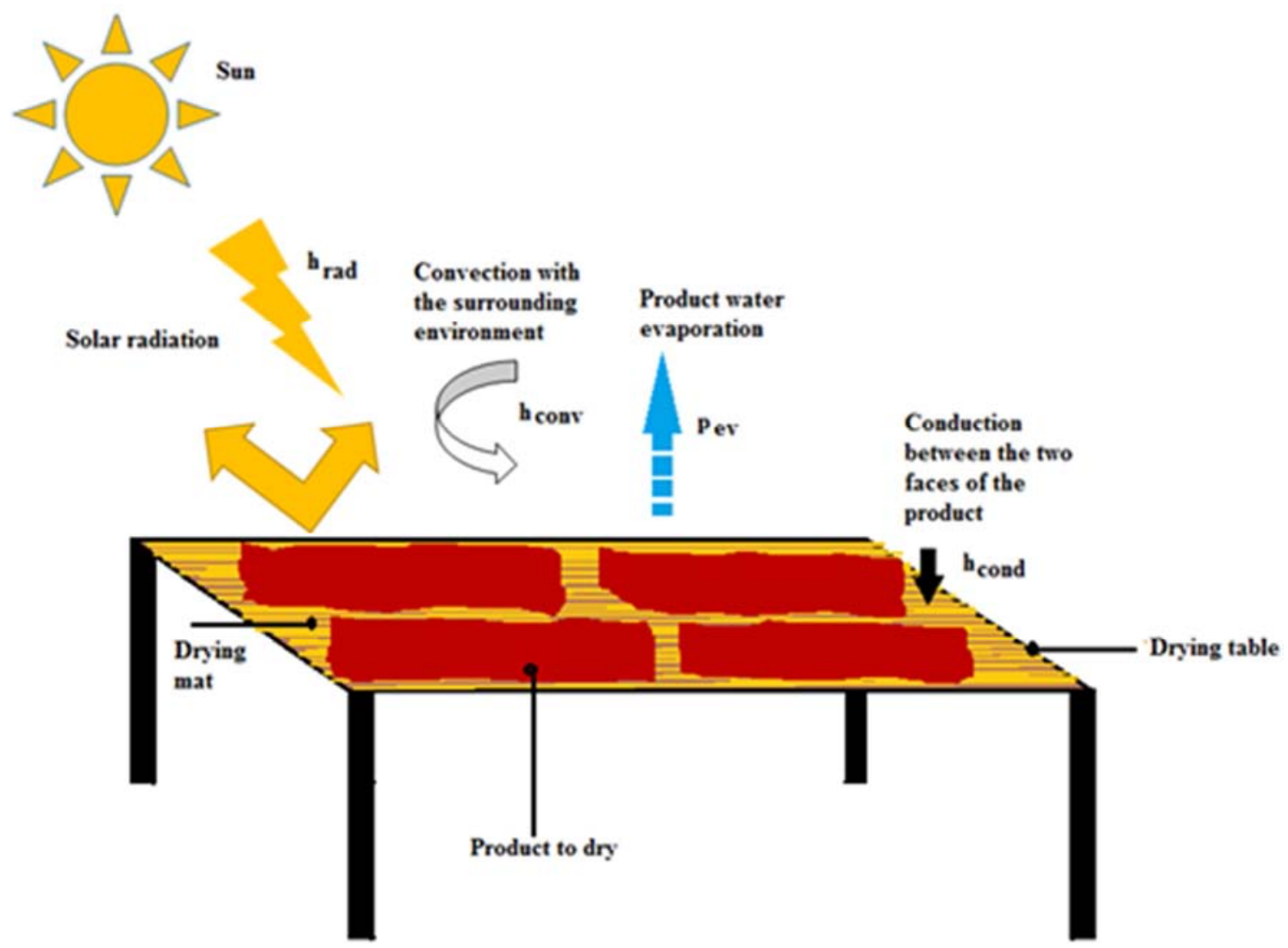

Figure 3. Heat exchange phenomenon of convective drying of meat slices in kilishi form.

\subsection{Mathematical Modeling}

\subsubsection{Simplifying Assumptions}

We consider that:

The drying process is done without climatic disturbance;

The temperature of the drying air is equal to the ambient temperature;

The air flow is parallel to the drying bed;

Convection is natural;

The exchange through conduction between the slices and the mat is neglected;

The slices of meat are opaque to solar radiation;

The physical properties of the slices of meat are considered to be homogeneous;

The effect of fat is negligible.

\subsubsection{Mathematical Modeling Equation}

Energy balance of the product on the top side.

$$
m p * C_{p-p} * \frac{d T_{P+}}{d t}=\alpha_{p} * S_{p} * R s g+h_{r a d} * S_{p} *\left(T_{v}-T_{P+}\right)+h c o n * S_{p} *\left(T_{a}-T_{P+}\right)+h c o n d * S_{p} *\left(T_{p+}-T_{P-}\right)-\dot{m} * L v
$$

$m p, C p-p, \alpha_{p}$ and $S_{p}$ respectively product mass, specific heat by mass of the product, product absorption coefficient and product surface.

$T_{p+}, T_{p-}$ and $T_{a}$ respectively temperature of the upper part of the product, temperature of the lower part of the product and ambient temperature.
$R s g, \dot{m}$ and $L v$ respectively global solar radiation on the product, mass flow of the product water evaporation and the latent heat of vaporization of the product water.

$h_{\text {rad }}, h_{c o n}$ and $h_{\text {cond }}$ respectively coefficient of transfer through radiation between the sky and the slices of meat, coefficient of thermal convection between the slices of meat 
and the ambient air and coefficient of thermal conduction between the top side and the bottom side of the slices of meat.

Energy balance of the product on the bottom side

$$
m p * C_{p-p} * \frac{d T_{P+}}{d t}=\text { hcond } * S_{p} *\left(T_{p+}-T_{P-}\right)
$$

Mass balance of the product

$$
\dot{m}=m p_{-} s\left(-\frac{d X}{d t}\right)
$$

The mathematical model of drying kinetics chosen to describe the drying process of meat slices in kilishi form is an empirical model inspired by the study of PP Tripathy, Subodh Kumar [5] and Mohamed Yacine NASR et al [6].

$$
\left(-\frac{d X}{d t}\right)=\left(\frac{X-X_{e q}}{X_{i}-X_{e q}}\right) * K_{0} * \exp (-K * t)
$$

With

$$
\begin{gathered}
K_{0}=1.005+4.58 * .10^{(-5)} * T_{a} \\
K=4.20 * .10^{(-5)}+2.15^{*} .10^{(-6)} * T_{a}
\end{gathered}
$$

$X, X_{i}$ and $X_{e q}$ respectively water content, initial water content and equilibrium water content $K$ and $K_{0}$ are the parameters of the model

\subsubsection{Correlations Used in the Model}

The correlations used in this study are taken from the literature. Thus, we have:

The coefficient of thermal convection between the slices of meat and the ambient air is given by the equation of Mc Adam [7]:

$$
h \operatorname{conv}=5.67+3.8 * V_{V}
$$

$V_{V}:$ wind speed

The coefficient of thermal conduction between the top side and the bottom side of the slices of meat is given by the relation:

$$
\text { hcond }=\frac{\lambda_{p}}{e_{p}}
$$

$\lambda_{p}$ and $e_{p}$ respectively thermal conductivity and product thickness

The coefficient of transfer through radiation between the sky and the slices of meat is given by the relation $[8,9]$ :

$$
\text { hrad }=\sigma \varepsilon_{p}\left(T_{P+}^{2}-T_{V}^{2}\right)\left(T_{P+}-T_{V}\right)
$$

$T_{v}:$ sky temperature

The temperature of the sky is given by the relation of SWINBANK [10]

$$
T_{V}=0.0552 T_{a}^{1.5}
$$

The latent heat of water evaporation on the product' surface is given by the relation [11] [12]:

$$
L v\left(T_{h}\right)=4186.5\left(597-0.56 * T_{h}\right)
$$

\subsubsection{Numerical Resolution}

The system of equations governing the outdoor-under the sun-drying process of meat slices consists of three (03) first order differential equations. To solve it, we used the $4^{\text {th }}$ order Runge-Kutta numerical method. The relative errors between the results of the numerical simulation and the experimental results are given by the statistical parameters calculated from the following formulae [13] [14]:

R-Square

$$
R^{2}=1-\frac{\frac{1}{n} \sum_{i=1}^{n}\left(\operatorname{Yexp}_{i}-\operatorname{Ymod}_{i}\right)^{2}}{\frac{1}{n} \sum_{i=1}^{n}\left(\operatorname{Yexp}_{i}-\overline{\operatorname{Yexp}_{i}}\right)^{2}}
$$

Mean Square Error

$$
M S E=\frac{1}{n} \sum_{i=1}^{n}\left(\operatorname{Yexp}_{i}-\operatorname{Ymod}_{i}\right)^{2}
$$

Root Mean Square Error

$$
R M S E=\sqrt{\frac{1}{n} \sum_{i=1}^{n}\left(\operatorname{Yexp}_{i}-\operatorname{Ymod}_{i}\right)^{2}}
$$

$Y \exp _{i}$ : experimental value of $\mathrm{Y}$

$Y \overline{\exp _{i}}:$ mean experimental value of $Y$

$Y \bmod _{i}:$ Model predictions value of $Y$

\section{Results and Discussion}

Experimental Results.

\subsection{Evolution of Product Surface Temperatures}

The figure below show the temperature evolution of the product' sides during the drying process. 


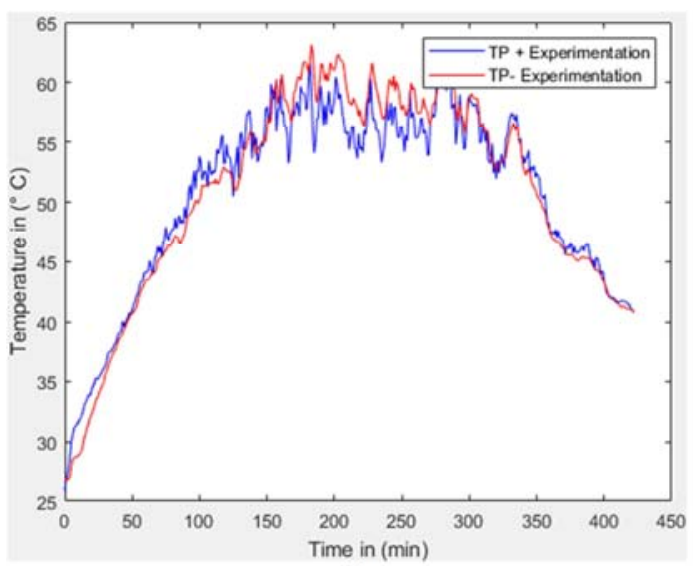

(a)

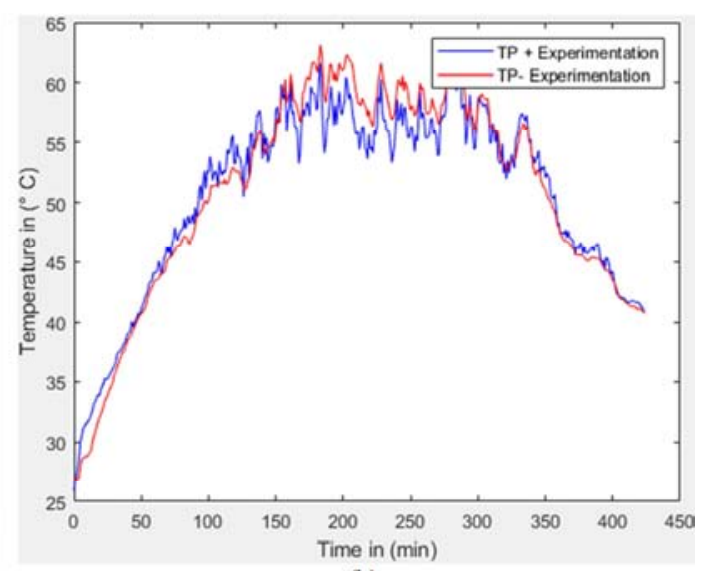

(b)

Figure 4. (a) and (b): Experimental curves of the temperature evolution of the product faces during the drying process.

Note that for the two samples A1 and A2, the change in temperature is almost identical under the same drying conditions.

\subsection{Evolution of the Product's Water Content}

The figure below show the evolution of the water content of the four samples of meat slices during the drying process.

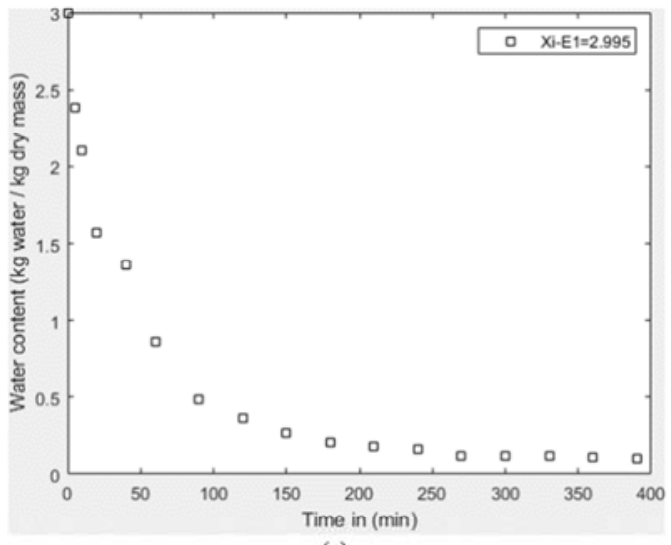

(a)

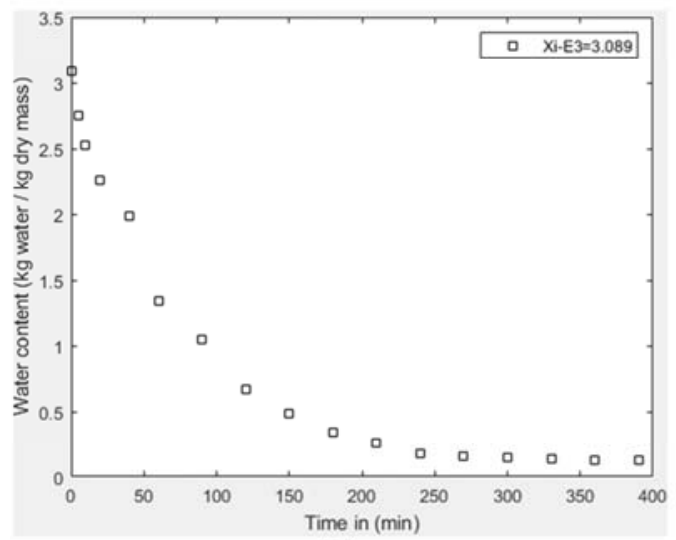

(c)

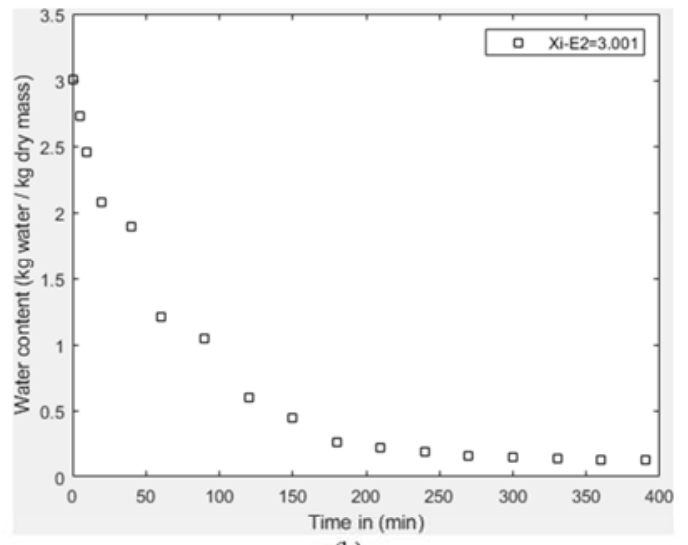

(b)

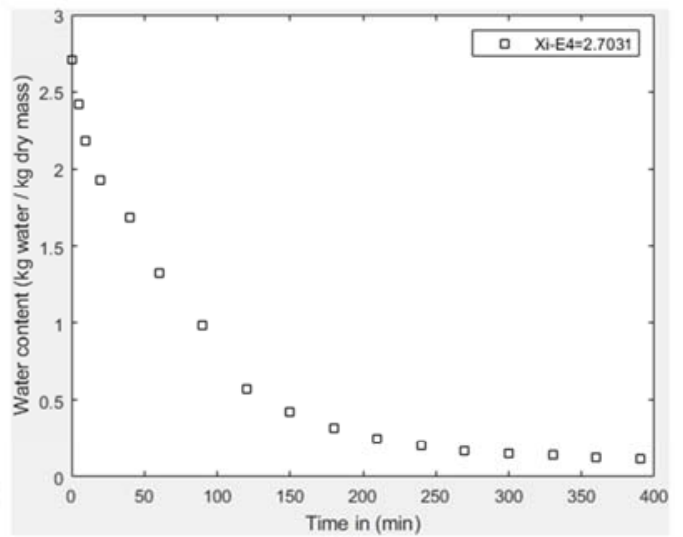

(d)

Figure 5. (a), (b), (c) and (d): Experimental curves of the change in water content of the four samples of meat slices as a function of time.

A stability of the product after 6 hours of drying is observed for each of the water content curves. At the end of this drying process, a dry-base percentage for the four samples is obtained, respectively $10 \%, 12.5 \%, 12.4 \%$ and $11.8 \%$. These dried samples are used for the roasting operation to obtain the Kilishi which is the final product.

\subsection{Evolution of the Drying Speed as a Function of the Water Content of the Product}

The figure below show the evolution of the drying speed as a function of the water content of the four samples of the slices. 


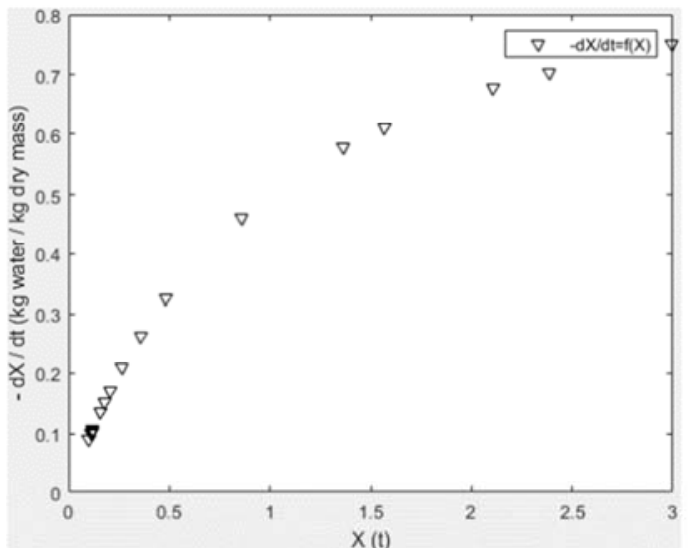

(a)

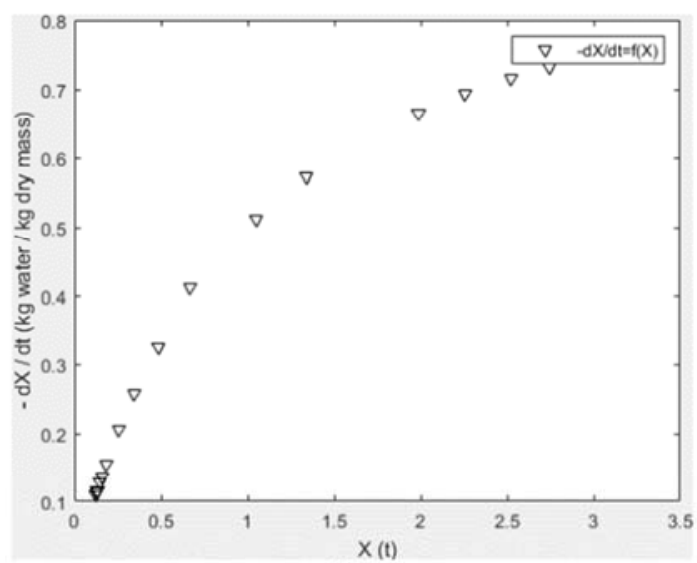

(c)

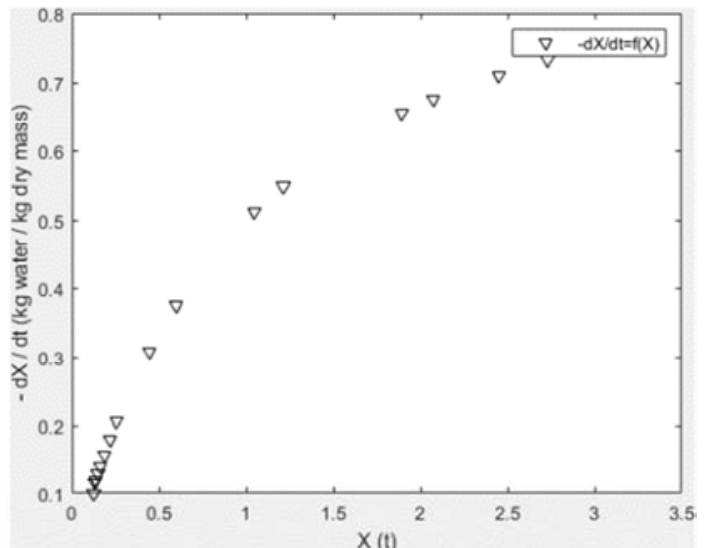

(b)

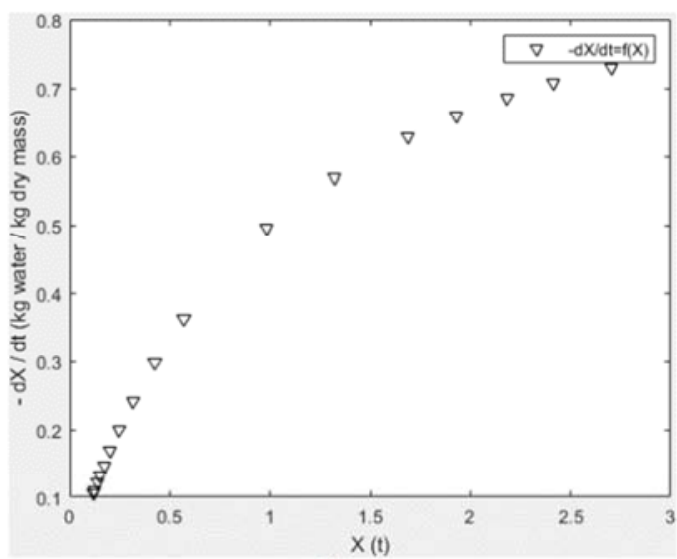

(d)

Figure 6. (a), (b), (c) and (d): Experimental curves of the evolution of the drying speed of the four samples of meat slices as a function of the product's water content.

The examination of the shape of these drying curves shows two drying periods. A first period during which the drying rate slowly decreases which can be considered as the phase at constant speed, and a second period with a significant decrease in the drying rate considered as the phase at decreasing speed. These two phases have also been observed by the work of A. TOM et al [15] on the solar drying of beef.

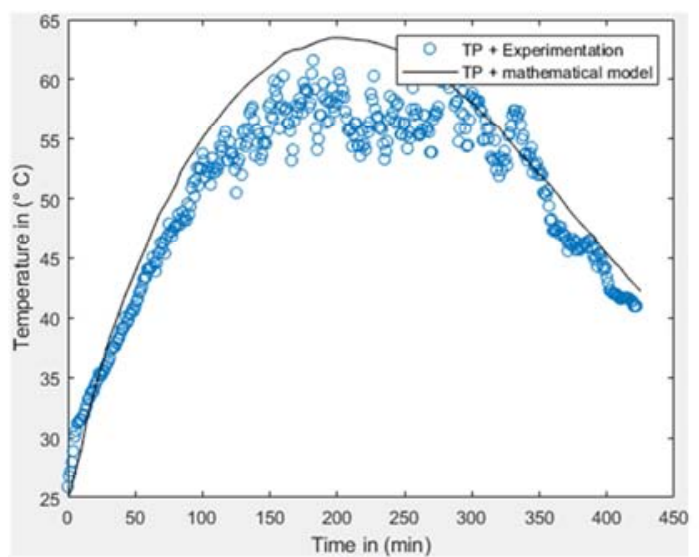

(a)

\section{Validation of the Mathematical Model}

\subsection{Comparison of the Temperatures of the Product' Surfaces}

The figure below represent the experimental and simulated results of the temperature evolution of the product faces during the drying process.

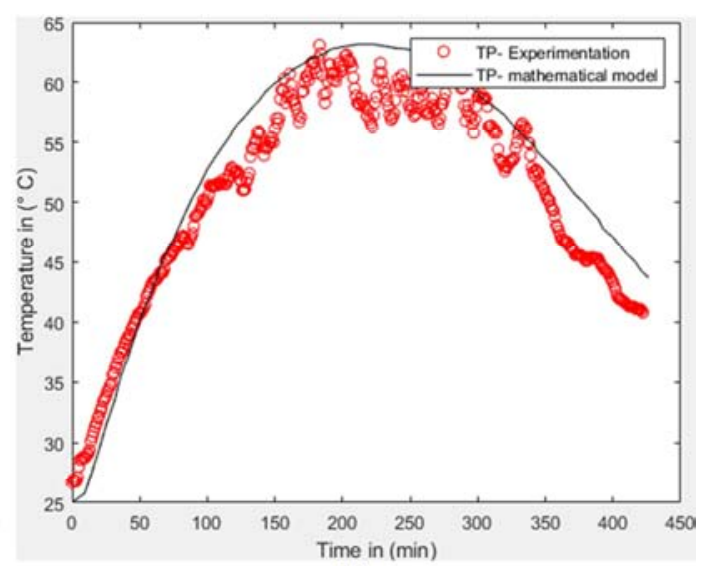

(b)

Figure 7. (a) and (b): Experimental and simulated curves of the evolution of the faces'temperatures. 
It is observed that the simulated curves match satisfactorily with the experimental curves. The examination of the values of the calculated statistical parameters shows an $\mathrm{R}^{2}$ value close to 1 and low values of MSE and RMSE. The table below shows the values of the calculated statistical parameters.

Table 6. Statistical parameters.

\begin{tabular}{llll}
\hline Product sides & $\mathbf{R}^{2}$ & MSE & RMSE \\
\hline Top sides of the product & 0.9915 & 0.6206 & 0.7878 \\
Bottom sides of the product & 0.9935 & 0.6383 & 0.7990 \\
\hline
\end{tabular}

\subsection{Comparison of the Water Content of the Product}

The figure below represent the experimental curves and the simulated curves of the four samples of meat slices.

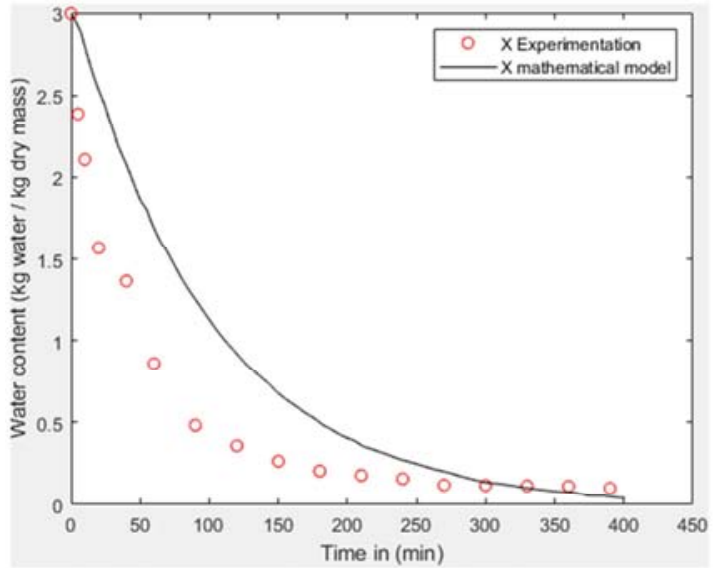

(a)

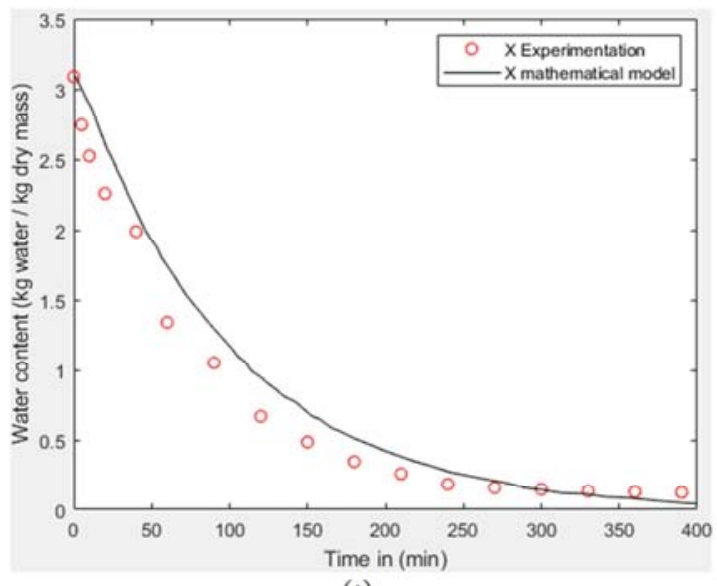

(c)

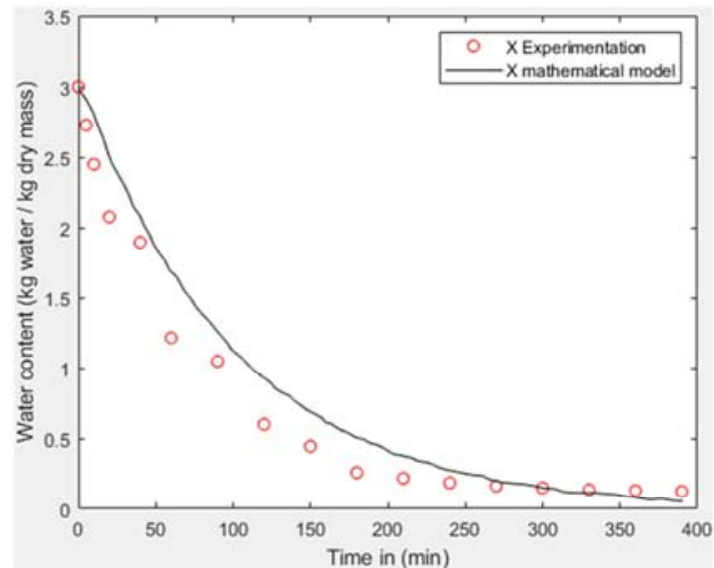

(b)

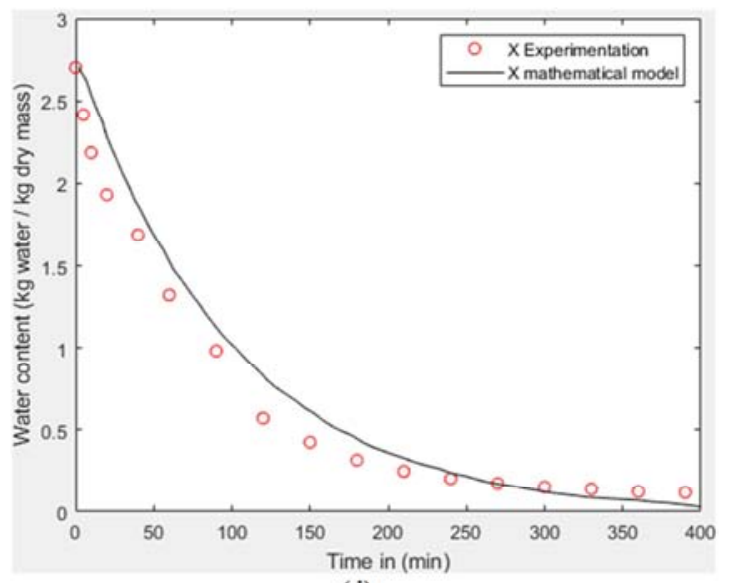

(d)

Figure 8. (a), (b), (c) and (d): Experimental and simulated curves of the evolution the four samples'water content as a function of time.

The values of the various calculated statistical parameters show an R2 value close to 1 and very low MSE and RMSE values. The table below indicates the values of the various calculated statistical parameters, thereby showing that the model describes in a satisfactorily the drying process.

Table 7. Statistical parameters.

\begin{tabular}{llll}
\hline Sample & $\mathbf{R}^{\mathbf{2}}$ & MSE & RMSE \\
\hline Sample B1 & 0.9763 & 0.0199 & 0.1410 \\
Sample B2 & 0.9901 & 0.0102 & 0.1008 \\
Sample B3 & 0.9938 & 0.0067 & 0.0816 \\
Sample B4 & 0.9946 & 0.0044 & 0.0660 \\
\hline
\end{tabular}

\section{Conclusion}

The experimental study of the outdoor-under the sun-drying in thin layers of meat slices in kilish form, in typical Sahelian climatic conditions, has shown the existence of drying phases: the phase at constant speed and the phase at decreasing speed. The model thus developed gives satisfactory results with regards to the experimental results. This is confirmed by the various calculated statistical parameters. These parameters show an $\mathrm{R}^{2}$ value close to 1 and very low MSE and RMSE values for the evolution of the meat slices' water content and the evolution of the temperatures of the product' surfaces 
during the drying process.

This drying process can be optimized by using solar dryers in order to reduce the drying time and also to protect the product against dust, flies and many other infestation.

\section{Acknowledgements}

I address my heartfelt thanks to Dr MAMAN SANI Laouali (Lecturer at Abdou Moumouni University, in charge of the Water and Environment Materials Laboratory of the Faculty of Science and Technology, Abdou Moumouni University), for allowing the access to Laboratory equipments.

I would like to thank M ADA ALMOU Mahamane (producer of kilishi at Terrain Musulman in Niamey-Niger) for his advice and his help in the preparation of thin slices of meat in the form of kilishi.

\section{References}

[1] https://fr.wikipedia.org/wiki/Conservation_de_la_viande.

[2] Ahmat TOM. Contribution au séchage solaire des produits carnés: modélisation et réalisation d'un séchoir adapté aux pays tropicaux. Thèse de doctorat en Génie énergétique. ParisTech: École Nationale Supérieure d'Arts et Métiers, 2015, 245 p.

[3] https://afriquematin.net/le-kilichi-la-viande-du-desert/.

[4] A. O. Dissa, E. S. Tiendrebeogo, S. Garba, J. Koulidiati, Modélisation et simulation du séchage solaire en couche mince de la Spiruline (Asthrospira platensis), Journal de la Société Ouest-Africaine de Chimie J. Soc. Ouest-Afr. Chim. (2016), 042: 1-7 21èmeAnnée, Décembre 2016.

[5] Tripathy, P. P. and Kumar, Subodh. (2008), "Determination of temperature dependent drying parameters for potato cylinders and slices during solar drying", Energy Conversion and Management, 49 (11), 2941-2948.

[6] Mohamed Yacine NASRI, Azeddine BELHAMRI, Simulation d'un sechoir solaire indirect a convection forcee pour les produits agroalimentaires, Sciences \& Technologie $\mathrm{B}-\mathrm{N}^{\circ} 44$,
(Décembre 2016), pp 57-62., Université des Frères Mentouri Constantine, Algérie, 2016.

[7] Mc Adam, W. H., Heat Transmission, 3rd ed. MC Craw Hill, New York (1954),

https://archive.org/details/in.ernet.dli.2015.238768/page/n53/ mode/2up.

[8] K. S. Ong, 'Thermal Performance of Solar Air Heaters: Mathematical Model and Solution Procedure', Solar Energy, Vol. 55, N², pp. 93-109, 1995.

[9] Rabéa. Kaoulal et al, Modélisation numérique d'un capteur solaire plan à air fonctionnant en régime transitoire en vue d'intégration au bâtiment, Conférence IBPSA France-Arras-2014, Université d'Adrar, Algérie 2014.

[10] SWINBANK W. C, Long-wave radiation from clear skies Quarterly Journal of the Royal Meteorological Society, vol. 89, issue 381, pp. 339-348 July 1963, https://doi.org/10.1002/qj.49708938105.

[11] Haoua AMADOU. Modélisation du séchage solaire sous serre des boues de stations d'épuration urbaines. Thèse de doctorat en Sciences pour l'ingénieur. Université Louis Pasteur-Strasbourg I: École doctorale MSII, 2007, 248p.

[12] A. BOUM, O. S. MAYI, B. DIBOMA et Z. NDASSA, Design, modélisation et optimisation d'un séchoir pour matériaux textile, Afrique SCIENCE 15 (4) (2019) 169 - 190, http://www.afriquescience.net.

[13] Doymaz, I. (2004) Convective Air Drying Characteristics of Thin Layer Carrots. Journal of Food Engineering, 61, 359-364. http://dx.doi.org/10.1016/S0260-8774(03)00142-0.

[14] E. S. Tiendrebeogo A. O. Dissa, F. Cherblanc, I. Youm, J-C. Bénet, A. Compaoré, J. Koulidiati, Characterization of Two Different Stumps of Spirulina platensis Drying: Assessment of Water Transport Coefficient. Food and Nutrition Sciences, 2015, 6, 1437-1449 http://dx.doi.org/10.4236/fns.2015.615148.

[15] Ahmat Tom, Mahamat Barka, Awarou Waste Aregba, Denis Bruneau. Convective drying of fresh beef: an experimental and modelling approach. Journal of Food processing and Preservation. 1745-1749. Doi: 10.1111/jfpp. 120508. 